\title{
PRÁTICAS EDUCATIVAS NO MUSEU DE ARTE DO RIO
}

\section{EDUCATIONAL PRACTICES IN MUSEU DE ARTE DO RIO PRÁCTICAS EDUCATIVAS EN EL MUSEU DE ARTE DO RIO}

\author{
DOI: http://dx.doi.org/10.5965/1984317815022019208
}

José Alberto Romaña Díaz

Universidade do Vale do Taquari jose.diaz@universo.univates.br

Angélica Vier Munhoz

Universidade do Vale do Taquari angelicavmunhoz@gmail.com

\begin{abstract}
RESUMO
A presente investigação partiu de uma doca de pesquisa, o Grupo de Pesquisa Currículo, Espaço, Movimento (CEM), para uma imersão no MAR - o Museu de Arte do Rio, no Rio de Janeiro. Mergulhar no MAR teve como propósito compreender de que modo um museu pode tecer tramas entre educação e a arte por meio de práticas educativas permeadas por um registro poético. Museu, educação, mediação e práticas educativas tornaram-se as noções para operar esta investigação. Destaca-se a aproximação de autores que têm se ocupado em estudar a instituição museu, como Tony Bennett, Carol Duncan e George Yúdice. A carta de MAReAR - processo que implicou mergulhar, ir e voltar, traçar mapas, tornando-se o próprio procedimento metodológico da referida investigação; possibilitou imergir em espaços ainda não pensados, marear territórios existenciais inéditos, vivenciar práticas educativas. Os resultados da investigação ajudaram a compreender que práticas educativas inventivas, construídas pelos educadores do MAR, podem ser produtoras de novas experiências de ensinar e aprender. Além disso evidenciou-se que a tensão existente entre professor e educador de museus parece um reflexo da tensão arte versus educação. Destaca-se que a presente investigação foi realizada com apoio da CAPES, Brasil, sob o Código de Financiamento 001.
\end{abstract}

Palavras-Chave: Museu de Arte do Rio. Arte. Educação. Práticas Educativas.

\section{ABSTRACT}

This investigation has departed from a research dock, the Research Group Curriculum, Space, Movement (CEM), for an immersion into MAR - the Art Museum in Rio de Janeiro. Diving in the MAR was intended to understand how a museum can weave plots between education and art through educational practices permeated by a poetic enrollment. Museum, education, mediation and educational practices have become the notions to operate this research. The carta de MAReAR -chart of navigation- as a process that involved diving and coming up, leaving and coming back, and tracing maps, which thus became the methodological procedure of this investigation. From this perspective, diving has enabled the immersion into not-yet-designed spaces, navigating uncharted existential territories, following flows, and experience educational practices. The results of this investigation have contributed to the understanding that inventive educational practices designed by MAR's gallery educators may produce new teaching and learning experiences. Also it showed that the tension between teacher and museum educator seems a reflection of the tension versus art education. Finally, it should be highlighted that this dissertation was supported by the Coordination for the Improvement of Higher Education Personnel (CAPES), Brazil, under the Funding Code 001

Keywords:Museu de Arte do Rio. Art. Education. Educational Practices. 


\section{RESUMEN}

Este trabajo partió desde el puerto de pesquisa: Grupo de Investigación Currículo, Espacio, Movimiento (CEM), rumbo a una inmersión en el MAR - Museu de Arte do Rio, Brasil. Sumergir en el MAR tuvo como propósito comprender de qué modo un museo puede tejer tramas entre educación y el arte por medio de prácticas educativas impregnadas de un registro poético. Museo, educación, mediación y prácticas educativas se convirtieron en las nociones para desarrollar esta investigación. Se destaca la aproximación de autores que se han ocupado de estudiar la institución museo, como Tony Bennett, Carol Duncan y George Yúdice. La carta de MAREAR - proceso que implicó sumergir, ir y volver, trazar mapas, convirtiéndose en el propio procedimiento metodológico de la referida investigación; posibilitó sumergirse en espacios aún no pensados, marear territorios existenciales inéditos, experienciar prácticas educativas. Los resultados de la investigación ayudaron a comprender qué prácticas educativas inventivas, construidas por los educadores del MAR, pueden ser productoras de nuevas experiencias de enseñanza y aprendizaje. Además, se evidenció que la tensión existente entre profesor y educador de museo parece un reflejo de la tensión arte versus educación. Esta investigación fue realizada con apoyo de la CAPES, Brasil, Código de Financiamiento 001.

Palabras Claves: Museu de Arte do Rio. Arte. Educación. Práticas Educativas.

\section{INTRODUÇÃO: DE UMA DOCA DE PESQUISA ATÉ UM MERGULHO EM UM ESPAÇO DE INVESTIGAÇÃO}

Estar inserido no grupo de pesquisa Currículo, Espaço, Movimento (CEM/ $\mathrm{CNPq} /$ Univates) permitiu-me perceber de maneira mais ampla as concepções de currículo, as diferentes configurações curriculares, os modos como se constitui o currículo em determinados espaços escolares e não escolares, e as possibilidades de criação de outras formas de pensar o currículo. A partir de autores da Filosofia da Diferença, tais como Deleuze e Guattari, Foucault e Nietzsche, entre outros, o grupo de pesquisa vem ocupando-se, desde 2013, em investigar as noções de currículo e de compreender os processos de ensinar e aprender produzidos por práticas educativas e artísticas em espaços escolares e não escolares. O Museu de Arte do Rio (MAR) é desde 2014 um dos espaços de investigação do Grupo CEM.

O meu lugar de partida - o Grupo CEM. É nesse lugar onde todas estas coisas acontecem ou aconteceram no meu corpo pesquisador. O grupo que me acolheu é o que estou chamando de doca, porto seguro, essa parte de um grande porto chamado academia, rodeado de cais, onde entro, junto a outros, para abrigarme, carregar e/ou descarregar, fugir do mau tempo, aprimorar, desconstruir, aprender, etc. Mas por que uma doca? As docas são bacias artificiais, de pequenas di- 
mensões, construídas em desvios das linhas normais de navegação do porto. Interessante saber que estas bacias artificiais conseguem estar em comunicação permanente ou temporária (dependendo das condições climáticas) com as águas dos lagos, dos rios e até dos mares.

Em meio à doca da pesquisa (Grupo CEM), parto para uma experiência com um espaço de arte (MAR) - espaço de investigação do Grupo CEM - e nele vivenciava práticas educativas pensadas na Escola do Olhar, propostas de um fazer com o outro, de um fazer junto, que ecoa em mim, que me instiga, a tal ponto de querer dar um mergulho no MAR e vivenciar as possibilidades que se tecem nas tramas da educação e a arte.

Empreendo a tentativa de trabalhar em um registro poético, com imagens e cenas que atravessam um espaço de arte. Dessa forma, "[...] Como falar dessas coisas comuns - que podem ser lidas na atmosfera de um romance, de uma pintura, de um filme, ou também sentidas no ambiente de uma aula -, como traduzi-las ou dar-Ihes materialidade e presença." (ADÓ; CORAZZA, 2015, p.273. Tradução nossa). No intento de materializar esses registros poéticos, em face das práticas educativas desenvolvidas no MAR. desta investigação, aciono movimentos que se constituem na instigação, imersão e experimentação na escrita (nem sempre nessa ordem) - aquilo que me cativa, provoca, cutuca, incomoda, me afunda no MAR.

Assim, junto ao MAR, participei de residências pedagógicas, visitas e cursos. Período de imersão no museu, durante o qual realizei observações, participo de atividades de formação, entrevistei educadores e gestores do MAR. Todas essas atividades, junto a atividades que visavam a aumentar minha capacidade pulmonar, compuseram parte dos meus equipamentos para mergulhar no MAR e permeiam esta investigação

A partir dessas questões que ecoaram na aproximação do MAR, saliento algumas que se encontram integradas e serão desenvolvidas em capítulos posteriores: Museu e Educação, Tessituras Marujas entre educação e arte, os fragmentos de práticas educativas tecidas no MAR. De início, é possível perceber que o museu, como instituição cultural público-privada, se encontra enredada em uma trama de movimentos político-econômicos dos quais se traçam diretrizes para o funcionamento da instituição. Na operatividade dessas diretrizes, vão se tecendo, sincronica- 
mente, pelos integrantes da instituição, outros movimentos de tipo micro. Nesses movimentos micros, que não existem sem os movimentos macros, os educadores do museu encontram espaços de criação, em meio a uma porosidade que perpassa os muros do museu e se espalha pela cidade do Rio de Janeiro.

\section{TESSITURAS MARÍTIMAS ENTRE EDUCAÇÃO E ARTE}

\subsection{MUSEU E EDUCAÇÃO}

Bennett, na sua obra intitulada The Birth of the Museum: History, Theory, Politics (1995), costura algumas hipóteses acerca do nascimento do museu, particularmente destacando que esse nascimento está imbricado com uma racionalidade política, termo que ele empresta do filósofo Michel Foucault para referir-se ao rastreamento do surgimento de novas tecnologias que visavam a regular a conduta de indivíduos e populações. Nessa perspectiva, é possível compreender que, junto à democratização dos espaços privados, os museus se abrem a um público mais amplo, em face da emergência de novas classes sociais, como a burguesia e a classe operária. Bennet (1995) afirma que o nascimento do museu como instituição estaria relacionado à ideia de coleção individual monárquica, presente em meados do século XVII. Trata-se do príncipe como colecionador, cuja atitude - a de colecionar constituiria um elemento de distinção social.

Já Duncan (1995) apresenta o nascimento dos museus a partir da memória cultural de um povo, um grupo social ou um grupo religioso. A autora destaca que a arquitetura dos primeiros museus foi uma tentativa de reproduzir as igrejas, motivo pelo qual muitos dos rituais religiosos também foram seguidos pelos museus. Tais rituais também estavam presentes nas bibliotecas e nas feiras, como aponta Bennet (1995), antigos gabinetes de curiosidades e de coisas exóticas procedentes de várias partes do mundo. Transpor os hábitos desses espaços para a esfera do museu equaciona uma nova passagem do espaço privado para o público em geral.

Outro fator chave para a constituição dos museus é o desenvolvimento científico dos séculos XVIII e XIX, que transporta para a vida comum a sua metodologia, ou seja, a organização da vida em função da lógica e da razão (DUNCAN, 1995; BARRETT, 2011). Em meio a esse movimento, as exibições de coleções eram con- 
stituídas por objetos históricos, artísticos ou científicos, governadas pelos princípios da taxonomia científica, de modo que a ênfase era colocada nas diferenças observáveis entre as coisas.

Independentemente da natureza desses museus - de arte, ciência ou história, eles contemplavam os discursos historicistas, científicos e universalizantes, que destacavam os objetos a seu cuidado e que remetiam ao imaginário nacional, àquilo que era comum aos diversos segmentos da nação. Nessa linha de raciocínio, Mörsch (2013) relata que os museus ingleses e franceses do século XIX e de início do século $X X$ valorizavam a aprendizagem, que lá se efetuava mediante o uso de objetos e imagens nacionais, com a seguinte observação: "Fue una iniciativa en nombre de la identidad nacional, cuyos resultados educativos fueron enfocados a mejorar la calidad de los bienes nacionales producidos en el contexto del conflicto colonial"1 (p.44).

Diante de tamanha tarefa, os museus tinham que deixar de ser espaços passivos de acúmulo de objetos, para assumirem um papel importante na interpretação da cultura e na educação do homem. Ocupavam, assim, novos lugares na representação do conhecimento científico, no fortalecimento da cidadania e no incremento da qualidade de vida (BENNETT, 1995). Para tal fim, os museus foram desafiados a criar metodologias especiais que tratavam de educar o público e de ensinar-lhe práticas culturais (DUNCAN, 1995).

Em suma, as configurações de cenário do nascimento dos museus vão desde o colecionador privado, representado na figura do soberano ou príncipe, que permitia acesso ao público, até a coleção pública, cujo objetivo era educar a população para uma identidade de caráter nacionalista, a partir de marcas diferenciadoras entre o comum e o exótico, constituindo uma história universal. Diante disso, Bennett (1995) também problematiza o conjunto de forças que dão lugar ao museu público na Europa e nos Estados Unidos da América, nesse processo da posse privada para a posse pública.

Dalla Zen (2011) e Duncan (1995) também nos ajudam a tensionar algumas questões: se os museus foram criados historicamente para o acesso restrito a al-

\footnotetext{
1 Foi uma iniciativa em nome da identidade nacional cujos resultados educacionais foram concentra-
} dos na melhoria da qualidade do patrimônio nacional produzido no contexto do conflito colonial. 
guns eleitos - uma vez que se afirmava que o povo não se interessava por arte e tampouco sabia comportar-se nos museus -, como abrir suas portas, tornando-os acessíveis a todos? Por outra via, Bennett (1995) auxilia-nos a questionar: a partir da abertura e acessibilidade dos museus, como manter a proteção de objetos culturais que outrora se mantiveram com acesso tão restrito?

Com efeito, diante de tal processo - passagem da posse privada para a posse pública e, portanto, acessibilidade e abertura dos museus -, torna-se necessário ordenar a sociedade, organizar o tempo e o espaço, disciplinar o corpo, por meio de dispositivos que se instituem a partir do século XVII, configurando-se como um poder disciplinar. Como destaca Foucault (1999), o poder disciplinar constitui-se em uma série de tecnologias de poder que se organizam em torno do homem-corpo e em certa economia política que é aplicada sobre ele. Assim, "[...] o corpo só se torna força útil se é ao mesmo tempo corpo produtivo e corpo submisso" (FOUCAULT, 2005, p.29). Dessa forma, sob o corpo-organismo individual, inscrevem-se dispositivos disciplinares, tecnologias de poder cujo fim é adequá-lo e normatizá-lo para servir a uma determinada sociedade. Uma sociedade de normalização, ensina-nos Foucault, caracteriza-se como "uma sociedade em que se cruzam a norma da disciplina e a norma da regulamentação, conforme uma articulação ortogonal" (1999, p.302). Portanto, para essa sociedade, imersa no processo de industrialização, não importa apenas as forças que disciplinam as condutas, mas também a eficácia daquilo que as sujeita (DÍAZ; MUNHOZ, 2018). Ademais, a grande explosão demográfica do século XVIII instaura uma nova dominação política do corpo, fabricando um tipo de homem e uma sociedade disciplinar necessários ao bom funcionamento da economia capitalista. Ainda a respeito do poder disciplinar, Foucault menciona:

[...] O poder disciplinar é [...] um poder que, em vez de se apropriar e de retirar, tem como função maior "adestrar": ou sem dúvida adestrar para retirar e se apropriar ainda mais e melhor. Ele não amarra as forças para reduzi-las; procura ligá-las para multiplicá-las e utilizá-las num todo. [...] "Adestra" as multidões confusas (FOUCAULT, 2005, p.143).

Não é à toa que, ao analisar os museus, Bennett (1995) retoma a análise de- 
senvolvida por Foucault para destacar elementos comuns a todas as instituições: prisões, fábricas, escolas, quartéis, hospitais, museus, etc. Todas elas estariam ao lado da produção de uma posição de poder e conhecimento com vistas a regular e adestrar a conduta de indivíduos. Desse modo, novas formas de comportamento poderiam ser efetivadas, as quais, internalizadas, se tornam imperativos de autovigilância. Vale lembrar que as coleções privadas que sustentaram os museus nacionais europeus foram compreendidos como verdadeiros conservatórios de obras sagradas (DALLA ZEN, 2017; DUNCAN, 1995; CASTRO; NIKITA, 2009). Portanto, o zelo, a disciplina, a postura do corpo, as instruções e as normas para visitas tornavam-se necessárias para efetivar a disciplinarização do corpo em uma instituição que privilegiava a conservação e consagração das obras. A imagem abaixo pode ser ilustrativa nesse sentido:

Figura 1 - Instruções para os visitantes do museu Hirshhorn, Washington.

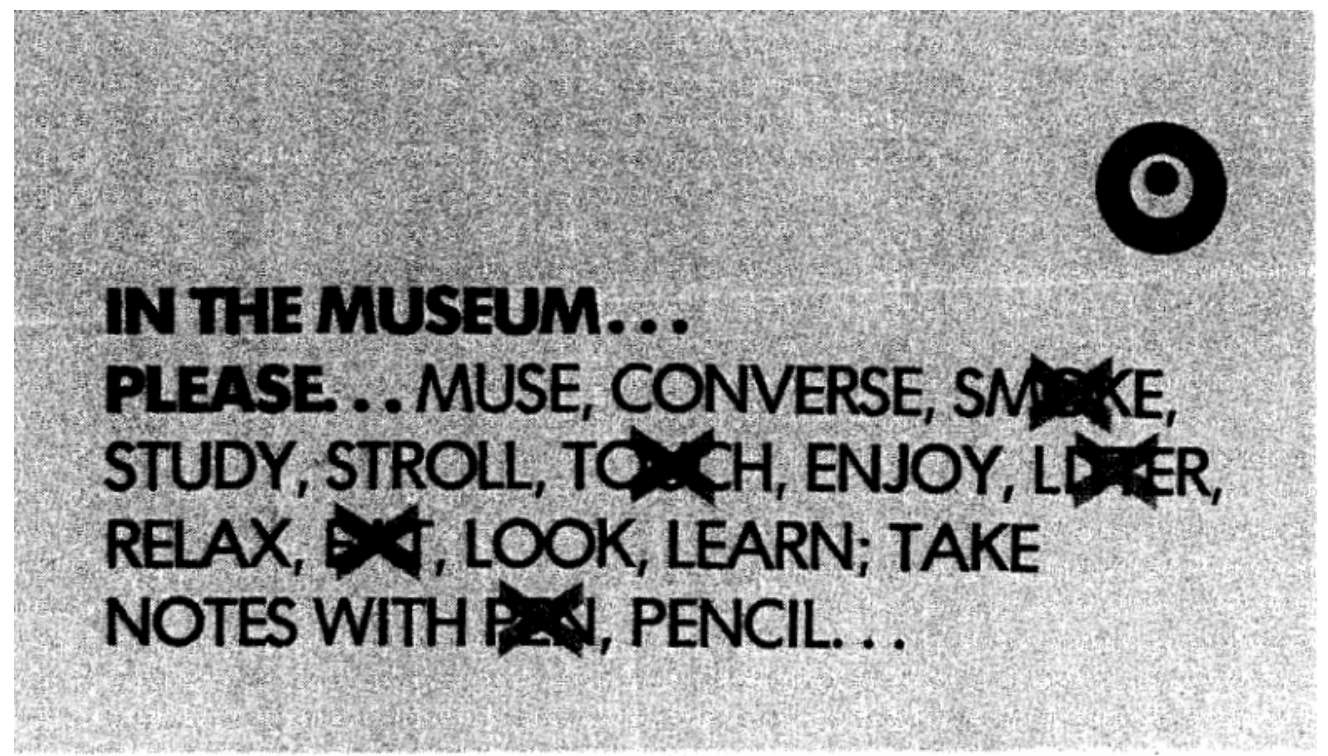

Fonte: Duncan (1995, p.10) $)^{2}$

O que Duncan (1995) nos traz para refletir é a evidência de rituais disciplinares, de códigos que foram se estabelecendo no intuito de modelar uma postura nos movimentos permitidos para as visitas desses espaços museais: palavras de

2 No museu... por favor... imagine, questione, não fume, análise, caminhe devagar, não toque, desfrute, não suje, relaxe, não coma, olhe, aprenda, tome notas não com caneta, e sim com lápis. 
ordem, gestos, instruções. Guedes (2015) também se refere a essa postura:

\begin{abstract}
Muitas vezes, nenhuma palavra precisa ser pronunciada, basta a arquitetura imponente, a equipe de segurança estrategicamente posicionada, os avisos de "não toque", tarjas no chão delimitando a aproximação com as obras, a iluminação e a aura sonora neutra dando o tom do espaço. Em outros casos, uma extensa lista de regras e orientações para visitas é disponibilizada no site das instituições, principalmente quando se trata de grupos agendados por escolas (GUEDES, 2015, p.141).
\end{abstract}

O museu, que até então fez uso do poder disciplinar mediante uma série de técnicas de adestramento e de regras de comportamento para circulação em seus espaços, também cria, assim, dispositivos de controle, que operam por meio da própria arquitetura imponente e de estratégias de segurança e controle.

O uso desses dispositivos de segurança e controle na gestão de espaços mostra que não eram suficientes tão somente o adestramento e a disciplina individual de corpos; era preciso também o controle das populações. Portanto, a partir de Foucault (1999), não interessa mais somente disciplinar as condutas, mas produzir formas de gestão e administração da vida das populações. Tal lógica também diz respeito aos museus, de maneira que se torna necessário incidir sobre os sujeitos, "[...] instrumentalizando-os para estar em um espaço de arte" (GUEDES, 2015, p. 34).

Portanto, com essa nova configuração das relações de poder, podemos falar de um modo de governamento do corpo e da vida. Trata-se de um poder sobre a vida, o qual Foucault vai chamar de biopoder. Com efeito, na medida em que esse poder sobre a vida é tomado pelo Estado, o filósofo o denomina de biopolítica. Assim, para Foucault, a biopolítica buscou, "[...] desde o século XVIII, racionalizar os problemas postos à prática governamental pelos fenômenos próprios de um conjunto de viventes constituídos em população: saúde, higiene, natalidade, longevidade, raças..." (FOUCAULT, 2008, p.431).

É dessa forma que Foucault (2008) nos ajuda a compreender que, toda vez que o poder do Estado não se concentra mais em fazer morrer, mas em fazer viver, se passa de um poder disciplinar de condução de condutas do indivíduo para condições que garantam que a população (enquanto força de trabalho) consiga viver 
e produzir mais. Em seu curso proferido no Collège de France entre 1978-1979, Foucault (2008, p.30) afirma: "[...] procurarei Ihes mostrar como todos os problemas que procuro identificar atualmente têm como núcleo central claro, esse algo que se chama população. Por conseguinte, e a partir daí que algo como a biopolítica poderá se formar".

A biopolítica, então, concentra-se na organização e na administração da vitalidade humana coletiva e individual. Trata-se de estabelecer mecanismos capazes de estimular a natalidade, prolongar a vida, prevenir epidemias, regularizar hábitos corporais, diminuir a extensão e intensidade das doenças, determinar os espaços/tempos de lazer. Estas estratégias de disciplinamento e condução das condutas mostram uma dupla transição: uma que passa do poder disciplinar para a biopolítica; outra que vai do liberalismo ao biopoder, quer dizer, um Estado que tem como objeto a população, e não mais o território (DÍAZ; MUNHOZ, 2018). Se tomarmos os museus a partir de tais práticas de governamento, poderemos perceber esse paradoxo, pois, "por um lado há uma retórica democrática vinculada ao acesso, um espaço aberto para a produção do debate público. Por outro lado no que diz respeito à sua função pedagógica, o museu opera de forma disciplinar, para formar sujeitos civilizados e nacionais" (YÚDICE, 2010, p.28).

Em relação aos museus, o Estado estaria desenvolvendo seu papel, pois "[...] priorizar práticas que visem à educação dos sujeitos coloca-se como uma potente estratégia de governamento da população" (GUEDES, 2015, p.45). O viés educativo dos museus tem no seu horizonte o desenvolvimento de estratégias que permitam a democratização do acesso ao conhecimento, a necessidade crescente de formação de público para a arte, bem como a produtividade da criação de estratégias de acessibilidade à arte (GUEDES, 2015). Nessa perspectiva, a inclusão e a democratização tornam-se estratégias para regular formas de habitar um espaço que busca tornar-se cada vez mais acessível a todos. Daí que o investimento do Estado no aperfeiçoamento de espaços que visam à cultura, além de ter como objetivo tornálos visíveis como instâncias públicas inclusivas, também tem como alvo uma educação igualitária para todos (BENNET, 1995; BARRETT, 2011).

Portanto, a gestão da educação da população produz um movimento biopolítico na/para a educação em museus por meio da democratização do acesso, 
da inclusão e das práticas educativas. Além disso, põe em prática estratégias que visam a tornar esses espaços atrativos e, sobretudo, capazes de produzir fruição, já que "[...] as funções básicas dos museus são a preservação, a investigação e a comunicação. E suas finalidades gerais são educação e lazer" (CHAGAS; NASCIMENTO JUNIOR, 2009, p.21). Nesse sentido, trata-se de convencer a população de que há formas de entretenimento cultural para ocupar o tempo livre, em detrimento das formas de lazer supérfluas e, inclusive, prejudiciais à saúde. Assim, na medida em que tais estratégias instrumentalizam os sujeitos para frequentarem os museus, também buscam governar as suas ações dentro desses espaços.

\subsection{MAR}

O Museu de Arte do Rio (MAR) foi concebido como um "presente" antecipado pelo aniversário de 450 anos da cidade do Rio de Janeiro, o MAR abriu suas portas no dia 01 de março de 2013, constituindo-se como uma das grandes instituições dentro do contexto de revolução cultural que engalana a Praça Mauá. Nasce, assim, o Museu de Arte do Rio como um espaço dedicado à arte e à cultura visual, buscando articular educação e arte, pensar o Rio de Janeiro por meio de uma leitura transversal da história da cidade, assim como desenvolver atividades que envolvem coleta, registro, pesquisa e preservação de bens culturais e sua devolução à comunidade (MAR, 2016). 
Figura 2 - Museu de Arte do Rio.

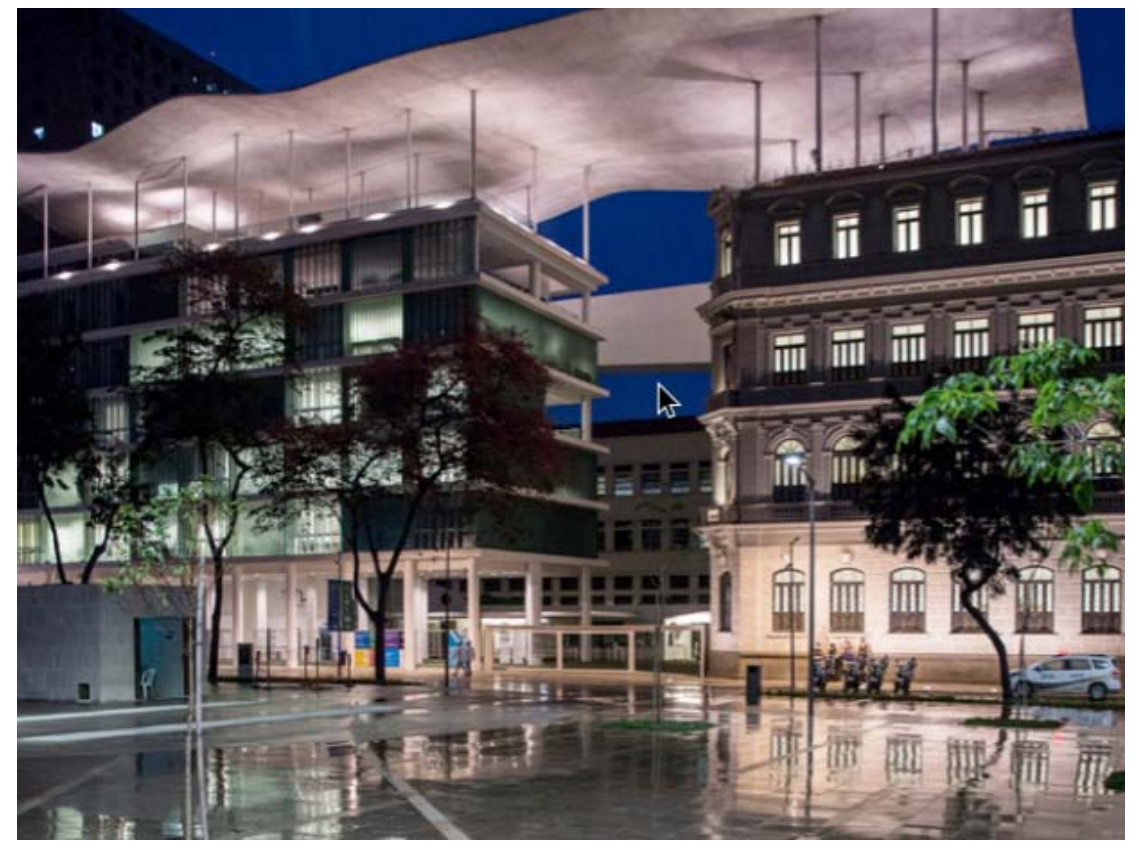

Fonte: MAR, 2016.

O MAR pode ser considerado um projeto poético, que apresenta uma reconfiguração admirável, destacando o sensível no âmbito de sua multiplicidade metafórica ao misturar-se com a natureza circundante da paisagem marítima carioca. A poética arquitetônica do museu é construída a partir do já existente, de um par de velhos e silenciosos testemunhos temporários, um deles um pouco mais antigo que o outro, sendo o mais novo mais alto que o mais velho. Aquele longevo, de estilo arquitetônico eclético, era chamado de Palacete Dom João VI (Portobras); já o mais moço, de estilo modernista, chamava-se Terminal Rodoviário Mariano Procópio. Vizinhos desde seus tempos áureos, ambos os prédios herdaram a garantia de permanência pela legislação. O fato é que os dois, ancorados no porto, expostos às inclemências do tempo, da maresia e dos infortúnios, sobreviveram no seu empenho de continuar a olhar para a Baía de Guanabara. Contudo, cabe lembrar que inicialmente se tinha a ideia de converter o primeiro prédio - Palacete Dom João VI - em Pinacoteca do Rio e talvez transformar o segundo em uma escola de arte.

O complexo arquitetônico foi composto por um teto em forma de cobertura fluida de concreto, simulando uma onda, a qual se tornou uma característica marcante do museu. Onda suspensa, movimento imóvel incessante que os dois prédios pare- 
cem burlar, ao mesmo tempo que o sustentam. Deslocamento sem locomoção, movimentos entre educação e arte impulsionados pelo vento do MAR. A onda aparece como horizonte no meio do grande vazio entre a Escola do Olhar e o Pavilhão de Exposições.

O outro ponto de união das duas estruturas é uma passarela suspensa, que sai da Escola do Olhar e conduz ao Pavilhão de Exposições, fazendo com que os visitantes precisem passar por ali para migrar da Educação à Arte. É uma passagem em um sentido só $(E \rightarrow A)$, e seu início é vigiado e assinalado por uma catraca. Vale a pena mencionar que o acesso é feito pelo térreo da Escola do Olhar, mediante elevador que chega até a praça suspensa, no quinto andar. Dessa forma, o Pavilhão de Exposições é percorrido de cima para baixo, e na saída encontra-se outra catraca, que fica próxima à bilheteria. 
Figura 3 - Vista do MAR: Onda e Passarela.

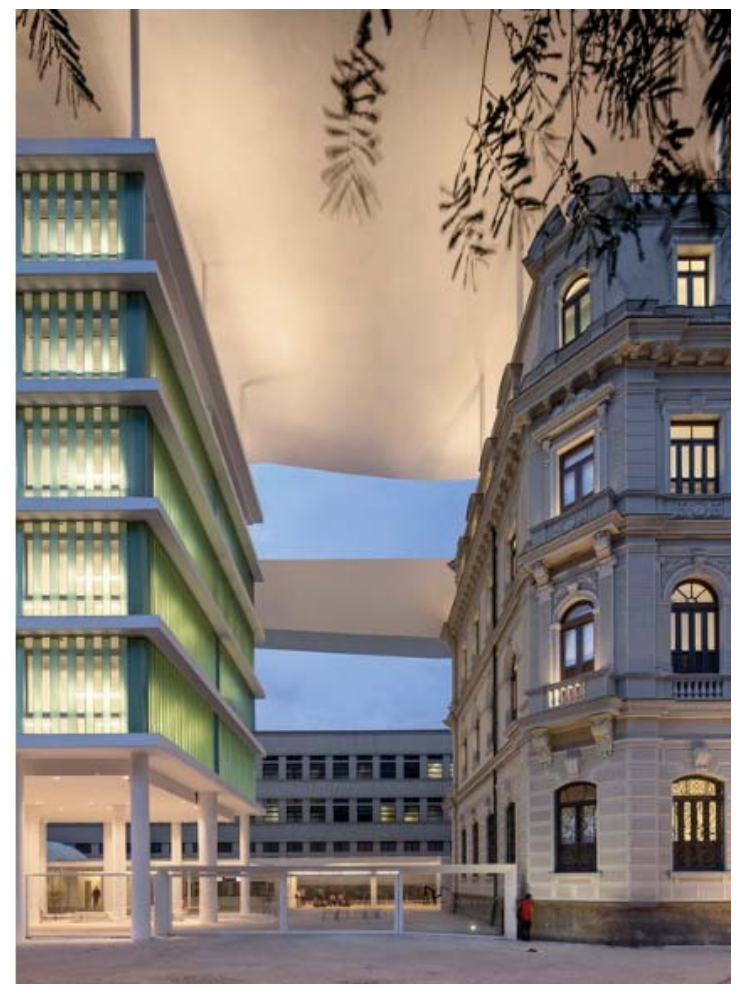

Fonte: Leonardo Finotti (2013) ${ }^{3}$

\subsubsection{Escola do Olhar}

Feito esse percurso pela história e geografia do MAR, vale ressaltar que o que nos interessa nesta pesquisa é a Escola do Olhar. Sediada no prédio cuja fachada é feita de paredes ininterruptas de vidro, a Escola do Olhar é o espaço onde se pensam as ações educativas do museu, lugar onde opera a gerência de educação, que tem como proposta o desenvolvimento de um programa educativo que conjugue arte e educação. Constituído como um espaço de formação continuada dos professores da rede municipal de ensino e de recebimento dos estudantes das escolas públicas e de outros visitantes, a Escola do Olhar propõe-se a estimular e disseminar a sensibilidade e o conhecimento. Suas proposições partem da compreensão da educação como prática de criação e experimentação pelos educadores do museu.

\footnotetext{
${ }^{3}$ Disponível em: https://goo.gl/g2NiAV
} 
O fazer do educador, nesse sentido, estaria mais no campo do fazer junto, fazer com - rearranjo que vai sendo construído entre educador e visitante em meio a uma instituição: o museu. Talvez essas práticas consigam ser reescritas nos arranjos com o público, na procura de outras formas de interagir ainda não pensadas, pois "[...] o método é duvidar do próprio método, para se dedicar ao lugar da pesquisa, invenção e descoberta" (MAR, 2016, p.13) em um espaço de criação e experimentação. Processo contínuo perpassado por decifrações, adaptações, aprofundamentos, traduções, reinvenções, complementações, (re)criações e novas problematizações. Trata-se de fazer do educador, pois, um artista do MAR, uma vez que o que resulta das práticas são percursos de aprendizagens e intervenções efetuadas pelos educadores durante esse processo de invenção.

Destaco, neste capítulo, três ênfases do trabalho realizado pela Escola do Olhar: as visitas educativas, as práticas educativas e os Programas de Formação com professores. A escolha dessas três ênfases se dão pelo fato de elas abordam mais diretamente as atividades que integram a arte e a educação, foco desta investigação.

\subsubsection{Visitas educativas}

Em relação às visitas educativas, Boing (2016, p.35) afirma que "[...] a metodologia de visita, a partir de eixos temáticos, permite que o educador, junto aos visitantes - estudantes e professores de escolas públicas, além de outros públicos explorem os conteúdos de todas as exposições do MAR". O programa de visitas tem por objetivo acolher os visitantes, na sua maioria, escolares. Nesse programa, atuam diretamente os educadores responsáveis pelo atendimento ao público. As visitas são planejadas a partir de quatro eixos temáticos, quais sejam: a) Vejo o Rio de Janeiro - dedicado a pensar a cidade, suas complexidades e potencialidades; b) Guardar para lembrar - voltado para questões de coleção, museu e memória; c) Meu corpo no Museu - consiste em experimentar o corpo pelo espaço do Museu e questionar as suas representações pelo viés da arte; d) Práticas Artísticas Contemporâneas visa aos processos criadores contemporâneos da arte.

As visitas educativas possibilitam a imersão das escolas, professores, alunos e público em geral, em sua grande maioria, a partir de agendamentos prévios, o que 
permite o planejamento das práticas educativas por parte dos educadores. Assim, a Escola do Olhar programa e planeja grande parte das visitas educativas, ação realizada pelos educadores, que se dedicam a pensar, a criar e a experimentar as proposições e práticas educativas do MAR. Trata-se, portanto, de um museu de arte aonde as pessoas vão não somente para visitar e conhecer ou apreciar as exposições, mas para interagir, experimentar, aprender. Ensinariam os educadores do MAR também a olhar? Este questionamento remete-nos a uma história relatada por Galeano (2002):

Diego não conhecia o mar. O pai, Santiago Kovadloff, levou-o para que descobrisse o mar. Viajaram para o sul. Ele, o mar, estava do outro lado das dunas altas, esperando. Quando o menino e o pai enfim alcançaram aquelas alturas de areia, depois de muito caminhar, o mar estava na frente de seus olhos. $E$ foi tanta a imensidão do mar, e tanto seu fulgor, que o menino ficou mudo de beleza. E quando finalmente conseguiu falar, tremendo, gaguejando, pediu ao pai: Me ajuda a olhar! (GALEANO, 2002, p.12)

Muitos visitantes do museu (sejam crianças, jovens, professores, cariocas ou visitantes de outros lugares de dentro e fora do Brasil) talvez peçam aos educadores ajuda para olhar, tal qual Diego. Ante esse pedido, os educadores do MAR veem-se desafiados a pensar práticas de mediação que provoquem fissuras no espaço que se situa entre a obra e o espectador, propiciando uma multiplicidade de olhares. Como uma conversa de mão dupla entre as narrativas ditas oficiais ou olhares oficiais para a obra e narrativas ou olhares produzidos a partir das práticas de mediação feita pelos educadores do MAR, há uma interação que possibilita pensar outras relações entre arte e educação (MARTINS, 2018).

\subsubsection{Práticas educativas}

As práticas educativas desenvolvidas pela equipe educativa do MAR são pensadas em relação às visitas dos públicos, sejam eles públicos de espaços escolares e não escolares, professores da educação formal e não formal, moradores da região portuária e da cidade do Rio de Janeiro, do Brasil ou de outros países. As atividades se tecem a partir das matérias das artes, das ciências e da filosofia, atravessadas por saberes e olhares que se entrecruzam nas exposições, onde ganham destaque os arranjos que os educadores estabelecem com o público (MAR, 
2016). Tais práticas educativas são produzidas pelos grupos de trabalho do museu: a) Narrativas fantásticas; b) Eu, a cidade e o outro; c) Forma, imagem e palavra; d) Acessibilidade.

Esses grupos constituem-se como espaços onde os educadores pensam e criam suas próprias práticas. No espaço desses grupos de trabalho, os educadores interagem com os cotidianos do museu, narram suas práticas realizadas, inventam outras pedagogias, pesquisam os conteúdos das exposições, planejam suas ações, estudam as complexidades dos métodos e metodologias para interagirem com objetos artísticos que propiciam a educação praticada nos/com os cotidianos do MAR (BOING, 2016).

O envolvimento com o grupo de trabalho é o que dá suporte e consistência ao educador para que ele crie os seus modos de praticar a educação no MAR. Contudo, cada prática é construída nas relações com os públicos, que sempre são únicos e diversos, gerando tensões e rearranjos, como destaca um dos educadores ${ }^{4}$ do museu

[...] quando as coisas são rearranjadas, a gente gera lugares de tensão, e em algum lugar é preciso que essa tensão reverbere, escape! $E$ esse lugar onde ela reverbera é onde eu me sinto atuando, onde eu sinto a gerência de educação desenvolvendo o trabalho (Educador do MAR)

O que o educador chama de rearranjo começa a nos dar pistas do lugar de uma prática, de um espaço onde se fazem acontecer os tensionamentos, pautados pelo papel de educador. Nessa perspectiva, afirma um dos educadores do MAR:

[...] a gente tem um processo que é muito baseado na troca, porque a gente tem um privilégio de não ter um conteúdo 'amarrado', digamos assim, previamente. Nós até temos interesses que são combinados previamente com professores, mas esses interesses, eles podem caminhar para outros interesses que surgem na visita (Educador do MAR)

Pode-se perceber que esta troca implica também um tempo de engajamento

\footnotetext{
4 Foram entrevistados educadores e gestores da Escola do Olhar sobre questões relativas às práticas pedagógicas desenvolvidas no museu. A identidade dos entrevistados será preservada.
} 
do público com o espaço, do educador com o público. Um tempo para que os corpos se sintam à vontade para habitarem o museu. Esse tempo de imersão e de experimentação no/do espaço é vivenciado pelo público em cada atividade, quando os educadores criam e realizam procedimentos e ferramentas que auxiliam nas trocas pedagógicas com os grupos.

\subsubsection{Formação com Professores}

No caso específico de formação com professores, a cada nova exposição, o MAR propõe um momento de experimentação e um pensar fazer (BOING, 2016), criando possibilidades de trabalho (na sala de aula ou no museu) com as obras apresentadas.

Por meio de uma gama de atividades desenvolvidas - na forma de workshops e palestras de curta e média duração, formação de mediadores, visitas mediadas, oficinas, convites a experimentar, encontros para educadores e seminários -, o MAR toma o programa de formação com professores como um espaço transdisciplinar de formação continuada, voltado para profissionais da educação que se interessem em conhecer as exposições e demais ações do museu. Tais ações pretendem tornar o museu um espaço favorável de investigação de práticas educativas, artísticas e culturais, nas quais as relações entre diferentes linguagens, pensamentos e práticas podem ser investigadas e experimentadas. O referido programa encontra-se dividido em quatro linhas de ação: a) Convite a experimentar; b) Cursos e seminários; c) Oficinas Práticas Artísticas Contemporâneas; d) MAR na rede.

Em cada uma dessas quatro linhas de ação, são oferecidas inúmeras atividades gratuitamente ao professores. Essas atividades são organizadas por meio de uma agenda, divulgada nas escolas e nas redes sociais. As atividades são específicas para professores. Alguns participam individualmente, devido a um interesse pessoal ou busca de alguma formação específica, e esse público é bem diversificado. Outros participam de formações organizadas para professores na rede de educação do Rio de Janeiro. Independentemente da forma como esses professores se aproximam das formações do MAR - de modo individual ou pela rede de educação -, elas parecem funcionar como um "[...]Potencializador de possibilidades e de mundos possíveis, isso permite aos professores e futuros professores arriscar-se a construir 
outras narrativas para repensar seus modelos educativos e, em consequência, os contextos escolares em que estão ou estarão inseridos" (JOVÉ; FERRERO; SELFA, 2017, p.3. Tradução nossa).

\subsection{CARTA DE MAReAR}

O presente estudo toma a carta de MAReAR como procedimento para traçar mapas. Por essa perspectiva, implica imergir em espaços ainda não pensados, marear territórios existenciais inéditos, dentro dos quais se faz possível agenciar novas relações com o outro e consigo mesmo (DELEUZE, 1988). A carta de marear inclui os desenhos que possibilitam o acompanhamento de fluxos, pois, dessa perspectiva, não há separação entre coleta, produção, interpretação, discussão dos dados e escrita do texto.

No período desta pesquisa, acompanho as linhas-correntes criadas, traçadas no MAR, marcando os pontos de ruptura, de fuga, de enrijecimento, identificando as possíveis zonas de tensão e analisando os cruzamentos dessas linhas e seus desdobramentos (PASSOS; BENEVIDES, 2015). Mergulho nesse espaço produtor de aprendizagem com o desafio de acompanhar os movimentos, ao mesmo tempo que eles se transformam e criam novas potências e fluxos. Assim, pode-se dizer que a carta está mais do lado de pensar os fluxos, os movimentos, as rupturas, as linhas traçadas (DELEUZE, 1988).

Aproximei-me do campo empírico por meio de diferentes estratégias e registros de diários de bordo. Para o acompanhamento dos processos pedagógicos desenvolvidos pelos educadores no MAR, foram realizados: análise dos materiais educativos do referido espaço de Arte; observações e registros em diários de bordo durante os tibuns no museu; entrevistas semiestruturadas com responsáveis pelo programa educativo do MAR e com diferentes atores participantes (gestores e educadores) nos programas na Escola do Olhar. Todas essas estratégias visaram a um mapeamento dos modos como as articulações entre mediação e aprendizagem vêm sendo pensadas no MAR.

\subsection{MAR EM FRAGMENTOS.}

Na continuação, apresento recortes de algumas práticas de mediação viven- 
ciadas no MAR durante o período de residências pedagógicas e visitas, realizadas em 2016 e 2017. Deparo-me com cenas, chamadas aqui de MAR em fragmentos Nessas práticas, era possível perceber uma tentativa de fazer com que os estudantes e outros públicos construíssem "[...] Suas próprias narrativas sobre os processos pedagógicos por meio da interação com a arte contemporânea" (JOVÉ; FERRERO; SELFA, 2017, p.3. Tradução Nossa), ou, como afirma um dos educadores no fragmento abaixo:

[...] propor que a gente faça coisas juntos, e pode ser uma coisa física, às vezes pode ser uma coisa do próprio corpo, a gente negociar: 'vamos fazer juntos esse percurso, vamos construir esse percurso'. (Educador do MAR)

Assim, em cada uma dessas experimentações, busco situar o contexto, descrever o procedimento realizado pelo educador e relatar as impressões e afecções produzidas em meu corpo.

\subsubsection{MAR em Fragmentos - Organizário das coisas do mundo}

Janeiro de 2017. Participantes do V Curso de Formação de Mediadores encontravam-se na Biblioteca do MAR. A atividade consistia em um grande livro colaborativo, livro em construção, no qual os participantes eram desafiados a categorizar todas as coisas do mundo de forma colaborativa. Esta prática havia sido criada pelos educadores no grupo de trabalho "Narrativas fantásticas". Os educadores mostravam o grande livro aos vários visitantes e os convidavam a seguir escrevendo. Tratava-se de um organizário, baseado no trabalho A biblioteca dos enganos, do artista Walmor Correa (2014), que coloca em tensão o método científico de classificação, ordenação e categorização das coisas. Para os educadores do museu, essa prática questiona como "[...] as ciências e as instituições artísticas são processos de invenção e também meios legitimadores de formas do saber" (MAR, 2016, p.63). Nessa experimentação, toma-se como pedra de toque a imaginação para estimular a descoberta e a invenção ao classificar-se por semelhanças ou elementos comuns às coisas do mundo. Reescrita de categorias em meio à compulsão organizatória atravessada pela multiplicidade de olhares que fazem com que as páginas do grande livro estejam em constante movimento; movimento incessante que vem a 
tensionar as categorizações existentes das coisas.

Figura 4 - Organizário das coisas do mundo.

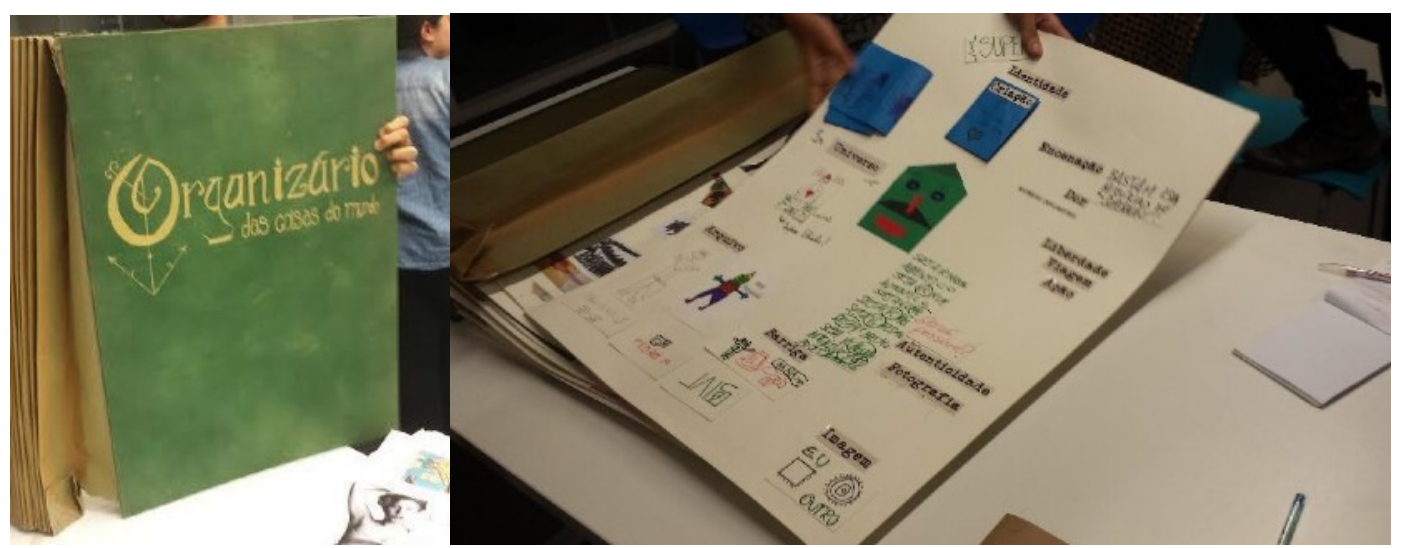

Fonte: Munhoz (2016)

Desafiados a categorizar as coisas, percebe-se como algumas categorias se sobrepõem e outras se contradizem. Da surpresa ou do desacordo, e diante deste último, uma vontade de reorganizar, corrigir, comentar, fazer notas elucidativas ou notas de rodapé. Nessa mistura, travavam-se novos rearranjos que possibilitavam pensar outras categorias. No final, uma sensação estranha: neste acúmulo de camadas e de múltiplas categorizações (por meio da memória individual ou coletiva), produz-se um livro infinito, em construção infinita, ao estilo da biblioteca borgeana.

\subsubsection{MAR em Fragmentos - Como viver no capitalismo sem dinheiro?}

Maio de 2016. Professores de escolas, uma educadora de projetos, dois Educadores. O "convite a experimentar" propunha a seguinte instigação: como viver (bem) no capitalismo sem dinheiro? Tal proposta fazia parte de uma exposição do artista José Miguel Casanova, a partir de uma provocação que pretendia evidenciar a naturalização das regras econômicas ou forma de nos relacionarmos com o capital. A proposta de José Miguel toma como base os modelos de arte e da educação para pensar coletivamente que outras organizações de formas de produção, de consumo e de troca podem ser consideradas como possíveis e desejáveis. Trata-se de um projeto artístico e educativo que busca criar modelos sensíveis de trocas, além de promover a investigação e a aprendizagem de práticas coletivas (MAR, 2016).

Já no início da atividade, uma mistura de surpresa e certo incômodo resultava 
da desconfiança da seriedade de tal proposta. Alguns cochichos: será mesmo? Retoma-se inúmeras vezes a pergunta em questão: como viver no capitalismo sem dinheiro? Junto a educadores do MAR, investigam-se o valor e as formas alternativas de troca e as coletividades na contemporaneidade. Logo o Banco dos Ireais nos é apresentado: "[...] O Banco de Tempo é uma ferramenta de desenvolvimento de trocas sociais que permite uma nova forma de relacionamento entre os membros de uma comunidade5". Instalado no primeiro pavimento do Pavilhão de Exposições, chega-se ao banco - um ambiente de praia, areia no chão, um grande relógio de areia, cadeiras de praia, um atendente, um tablet para realizar o cadastro e uma condição: tirar os sapatos para ingressar. No tablet, testemunhas de usuários do banco, anúncios de troca, oferta e demanda de serviços colaborativos.

\subsubsection{MAR em Fragmentos - O Nome do Medo}

Outubro de 2016. Parque Lage, sala grande, aproximadamente 15 crianças, quase a mesma quantidade de adultos. Artista, educadores do MAR, funcionários do AVE/Lage, residentes de design, professores, cuidadores, pesquisadores, fotógrafo. O tema: falar do medo, trazer os temores à tona - proposta da artista Rivane Neuenschwander, que buscava trazer elementos da psicanálise para pensar os medos das crianças. Lápis preto, lápis de cor, canetinhas, canetas, canetões, pincéis, apontadores, folhas, réguas, borrachas, papéis de diferentes texturas e cores, telas, tesouras de vários tipos, fios, lãs, agulhas, alfinetes, giz de tecido, fitas adesivas, fitas métricas, botões, materiais de diferentes brilhos e cores, e materiais próprios da área de corte e costura funcionavam como ferramentas para que o público - nesse caso, crianças - se sentisse encorajado a listar e desenhar os seus temores, assim como criar capas para proteger-se de seus medos.

5 http://bancodosirreais.org.br/ 
Figura 5 - Capas contra o medo.
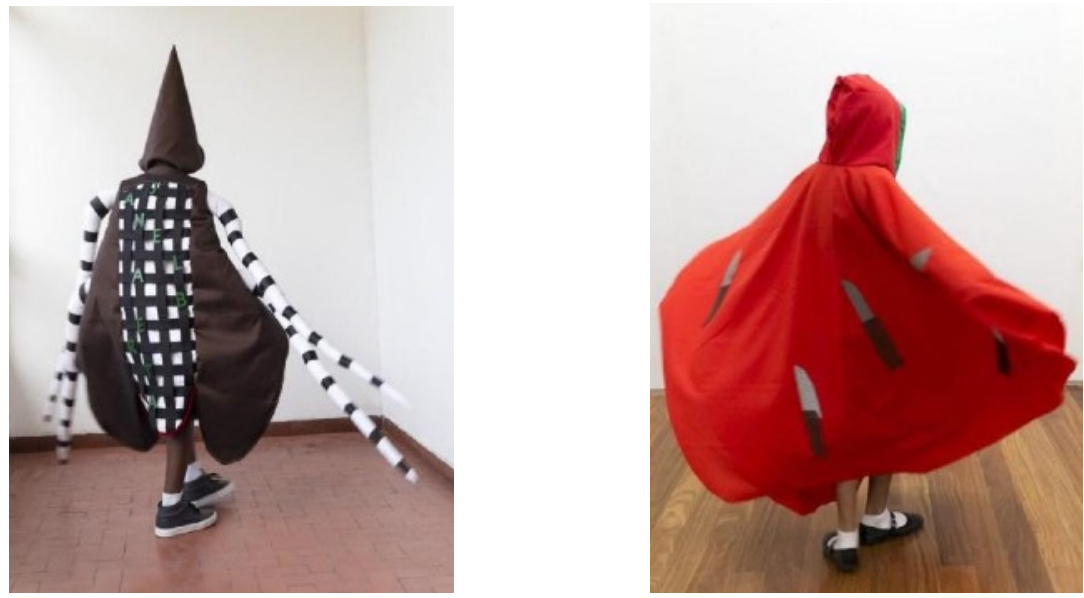

Fonte: Rivane Neuenschwander (2016)6.

Uma menina de nove anos, a quem chamarei de Naqdin, dizia que seu medo era o da escuridão. Então, fez um desenho prévio para a capa, usando muitas cores. Junto com Naqdin, vou até o lugar onde permanecem alguns materiais, fazemos o percurso juntos, e ela escolhe o que considera necessitar para o seu propósito. Depois de terminar a sua coleta inicial, começa a botar as mãos na massa. Pinta, tira, cola, puxa, mexe. "Assim não, é assim", sussurra. Pinta, costura, escreve... Pronto! No cocuruto da sua obra-prima, Naqdin fica contemplando o fruto de seu trabalho de diversos pontos de vista, com uma satisfação ilimitada.

\section{CONSIDERAÇÕES FINAIS: DO VENTO E DAS ONDAS DO MAR}

Marear, marujar, marluar, marlevar, marsoar, tibungar. Ao percorrer as práticas educativas desenvolvidas na Escola do Olhar do MAR, percebo a subversão de formas de mediação tradicional, as quais, na sua maioria, são modos de transmissão de informações acerca do acervo, procurando a fidelidade ao original. Constato novamente que se trata de um espaço onde ocorrem relações, práticas, tensionamentos, que estão diretamente vinculados ao lugar que os educadores ocupam no MAR, ou seja, um lugar de criação em meio ao estar entre - a obra e o público, a escola e o museu. Tais práticas não estão dadas, não existem a priori, mas talvez o desafio 
esteja em, a cada vez, inventar, criar, transcriar procedimentos tradutórios que carregam a vivência de novos problemas, que vão além de reconhecer, compreender formas de interpretação já dadas. Compreendo que tais práticas buscam "experimentações de desterritorialização, para dotar os originais de novos contornos, modelos, formas, gostos, vocabulários, sintaxes" de elementos educacionais que promovem a porosidade "[...] entre ações de pesquisa e prática docente com as diversas manifestações artísticas, filosóficas e científicas" (CORAZZA, 2015, p.114).

É possível perceber que o museu, como instituição cultural público-privada, se encontra enredado em uma trama de movimentos político-econômicos, pelos quais se traçam diretrizes para o funcionamento da instituição. Por um lado, "[...] não é difícil pensar no museu como um espaço controlado, afinal, há uma série de regras impostas pela condição de patrimônio de muitos objetos e obras do museu" (BOING, 2016, p.39). Por outro, percebo um forte disciplinamento das relações que se instauram em um espaço tão enciclopédico como o museu. Destaco aqui a grande influência nos corpos, corpos moldados, pois, supostamente, o museu é um lugar para caminhar lentamente, fazer silêncio - por isso o som de pneus furados feito por algumas pessoas, a pose de pensador enigmático, não tocar, não comer, não beber, não...

Aproximando-me do final, destaco a tensão professor/educador que pode ser evidenciada na fala do diretor do museu, Herkenhoff: "o professor não é o que não sabe, é o que pode. Se você diz que uma curadoria é um saber superior, você diz que o professor, que rala com a criança, não sabe. Claro que ele sabe, inclusive dar a dimensão da incomunicabilidade" (CANÔNICO; CYPRIANO, 2013). Destravar as relações de tensão que possam apresentar-se entre professor e educador do museu parece-me um reflexo da tensão arte versus educação. A favor dos educadores de museu, especificamente do MAR, estaria o fato de uma maior imersão e contaminação em meio à arte, o que redundaria em um olhar mais estético e poético. Já no caso do professor, às vezes, não há essa contaminação estética na sua formação, ou seja, não há uma formação pedagógica estético-artística.

\section{REFERÊNCIAS}


ADÓ, M. D. L.; CORAZZA, S. M. La escrita sociográfica como didáctica transcreadora y productora de presencia. ETD: Educação Temática Digital, Campinas/SP, v. 17, n. 2, p. 271-288, maio/agos, 2015. Disponível em: <https://goo.gl/2tdeMC>. Acesso em: 25 mai de 2018.

BARRETT, J. Museums and the Public Sphere. Chichester: Wiley-Blackwell, 2011, 204 p.

BENNETT, T. The Birth of the Museum: History, Theory, Politics. London and New York: Routledge, 1995, $278 \mathrm{p}$.

BOING, Maria Clara B. A educação praticada no/com o MAR: o que nos dizem gestos e narrativas dos educadores do museu? 2015. 106 f. Dissertação (Mestrado em Educação) - Programa de Pós-Graduação em Educação, Universidade do Estado do Rio de Janeiro (UERJ), Rio de Janeiro, 2016.

CANÔNICO, M. A.; CYPRIANO, F. Leia a íntegra da entrevista com Paulo Herkenhoff, diretor do Museu de Arte do Rio. Ilustrada, Folha de São Paulo. São Paulo, 28 fevereiro 2013. Disponível em: <https://goo.gl/XVk3oo>. Acesso em : 5 de mai de 2018.

CASTRO, M. V.; NIKITA, D. Breaking the Rules: Education and Post-Colonialism. Diaphanes, Zürich, v. 12, p. 317-332, 2009. Disponível em: <https://goo.gl/AHFfZc>. Acesso em : 15 de jul de 2017.

CHAGAS, M.; NASCIMENTO J. Subsídios para a criação de Museus Municipais. Rio de Janeiro: Ministério da Cultura/Instituto Brasileiro de Museus e Centros Culturais/Departamento de Processos Museais, 2009, 40 p. Disponível em: <https://goo.gl/Pqsrto>. Acesso em: 10 de jul de 2018.

CORAZZA, S. Didática da tradução, transcriação do currículo (uma escrileitura da diferença). Pro-Posições. v. 26, n. 1. Campinas,SP. 2015. Disponível em: <https://goo.gl/ JCSKJ7>. Acesso em: 22 set 2017.

DALLA ZEN, Laura Habckost. O dispositivo pedagógico da arte. 2011. 108f. Dissertação (Mestrado em Educação) - Programa de Pós-graduação em Educação, UFRGS, Porto Alegre, 2011.

DALLA ZEN, Laura Habckost. O lugar das experiências culturais na constituição de um ethos docente. 2016. 203 f. Tese (Doutorado) - Programa de Pós-graduação em Educação, UFRGS, Porto Alegre, 2017.

DELEUZE, G. Foucault. Minneapolis: University of Minnesota Press, 1988b, 209 p. Tradução de Seán Hand.

DÍAZ. J. R.; MUNHOZ, A. V. Economia Ambiental y Biopolítica: a experiência de uma escola colombiana. Revista Perspectiva. Florianópolis, v. 36, n. 1, p. 296-307. 2018.

DUNCAN, C. Civilizing Rituals: Inside Public Art Museums. New York: Routledge, 1995, $178 \mathrm{p}$.

FOUCAULT, M. Em defesa da sociedade. São Paulo: Martins Fontes, 1999, 357 p. Tradução de Maria Ermantina Galvão.

FOUCAULT, M. Vigiar e Punir: nascimento da prisão. 30. ed. Petrópolis: Vozes, 2005, 288p. Tradução de Raquel Ramalhete. 
FOUCAULT, M. Nascimento da biopolítica. São Paulo: Martins Fontes, 2008, 363 p. Tradução de Eduardo Brandão.

GALEANO, E. O livro dos abraços. Porto Alegre: L\&PM, 9.ed, 2002, 219 p.Tradução de Eric Nepomuceno.

GUEDES, Betina S. Nos arquivos da bienal do mercosul: democratizar, educar, investir. 2015. 228 f. Tese (Doutorado) - Programa de Pós-graduação em Educação, UNISINOS, Porto Alegre, 2015.

JOVÉ, G. M.; FERRERO, M. O.; SELFA, M. S.. A la derriba: una propuesta de enseñanza y aprendizaje a través del arte contemporáneo. ASRI: Arte y sociedad. Revista de investigación. Málaga/ESP, n. 12, p. 15-25, 2017. Disponível em: < https://goo.gl/es7Vpm>. Acesso em: 15 de agos de 2018.

MARTINS, Mirian Celeste. Verbete Mediação. In: Instituto Brasileiro de Museus. Caderno da Política Nacional de Educação Museal. Brasília, DF: IBRAM, 2018, 132 p

MÖRSCH, C. En una encrucijada de cuatro discursos. Educación en museos y mediación educativa en la documenta 12: entre la afirmación, la reproducción, la deconstrucción y la transformación. In: CEVALLOS, A. (org.). Contradecirse una misma, Museos y mediación educativa crítica. Quito: Alcaldía de Quito. 2013, 213 p. Traducción de N.Landkammer; C. Molestina; J.Rodrigo. Disponível em: <https://goo.gl/fTvHfY>. Acesso em : 10 de outu de 2016.

MUSEU DE ARTE DO RIO (MAR). Escola do Olhar: práticas educativas do Museu de Arte do Rio 2013-2015; Melo, J. (Org). Rio de Janeiro: Instituto Odeon, 2016, 103 p.

PASSOS, E.; BENEVIDES, R. A cartografia como método de pesquisa-intervenção. In: PASSOS, Eduardo.; KASTRUP,Virgínia \& DA ESCÓSSIA, Liliana. (Orgs). Pistas do método da cartografia: Pesquisa-intervenção e produção de subjetividade. Porto Alegre: Sulina, 2015, p.17-32.

YÚDICE, G. Museu molecular e desenvolvimento cultural. In: NASCIMENTO JUNIOR, José do (Org.). Economia de museus. Brasília: MINC/IBRAM, 2010, p.21-54. 